\title{
The Relationship between the Typhoon Storm in Fujian and Circulation Circumstances
}

\author{
Jinyu Zeng, Yi Lin, Conghui Gao \\ Fujian Meteorological Observatory, Fuzhou, China \\ Email: zjy10218@126.com
}

How to cite this paper: Zeng, J.Y., Lin, Y. and Gao, C.H. (2018) The Relationship between the Typhoon Storm in Fujian and Circulation Circumstances. Journal of Geoscience and Environment Protection, 6, 277-289.

https://doi.org/10.4236/gep.2018.64017

Received: March 2, 2018

Accepted: April 13, 2018

Published: April 16, 2018

Copyright $\odot 2018$ by authors and Scientific Research Publishing Inc. This work is licensed under the Creative Commons Attribution International License (CC BY 4.0).

http://creativecommons.org/licenses/by/4.0/

\begin{abstract}
The cases of landing and impact of the heavy rain of typhoon in Fujian are analyzed. From the research of the mainly weather systems which caused heavy rain and the distribution characteristics of atmospheric circulation situation field, we conclude that on the basis of Fujian special geographical location and terrain, there are four types (easterly jet, warm-type sheer, inverted V-shaped trough of typhoon, westerly trough) are conductive to the circulation patterns of causing the heavy rain of typhoon. Through studying a number of typical model cases of heavy rain of typhoon, we can reveal the mechanism which causes the heavy rain of typhoon by the mostly influencing systems in different circulation backgrounds and the causes of the heavy rain of typhoon.
\end{abstract}

\section{Keywords}

Typhoon, Heavy Rain, Circulation Circumstances

\section{Introduction}

Heavy rain of typhoon (referring to the tropical cyclone over the intensity of tropical storms, the same below) is a major summer disaster in Fujian. The loss caused by the heavy rain of typhoon is particularly serious. In particular, the typhoon circulation system in the interaction of the environmental field, as well as certain special topographical conditions in Fujian leads to the development of MCC to generate mesoscale rainstorm. Although the generation of heavy rain of typhoon is related to the typhoon intensity and structure of its own, moving path, terrain, atmospheric circulation background and many other factors, the circulation situation field plays a decisive role. A certain circulation situation field not only affects the movement path of the typhoon, the structure and in- 
tensity of typhoon to a certain extent, thus affects the typhoon rainfall intensity and distribution of drop zone [1]-[10]. In this paper, the cases of landing and impact of the heavy rain of typhoon in Fujian are analyzed. From the research of the mainly weather systems which caused heavy rain and the distribution characteristics of atmospheric circulation situation field, we analyze that the circulation features which occur the heavy rain of typhoon on the basis of Fujian special geographical location and terrain and on the different environmental conditions of circulation situation field. Through studying a number of typical model cases of heavy rain of typhoon, we can reveal the mechanism which causes the heavy rain of typhoon by the mostly influencing systems in different circulation backgrounds and the causes of the heavy rain of typhoon.

\section{The Relationship between the Typhoon Storm and Circulation Circumstances}

\subsection{The Definition of Heavy Rain of Typhoon}

In the cases of landing and impact of the heavy rain of typhoon in Fujian from 1960 to 2017, the cases of 24 hours daily precipitation of two and more than two stations that $\geq 100 \mathrm{~mm}$ are defined as heavy rain of typhoon. From 1960 to 2017, a total of 164 typhoons had occurred 250 heavy rain of typhoon.

\subsection{The Circulation Background Classification of Heavy Rain of Typhoon}

The generation of heavy rain of typhoon is related to the typhoon intensity and structure of its own, moving path, terrain, atmospheric circulation background and many other factors. In particular, whether heavy rain appears in the periphery spiral clouds band before typhoon's landing and in the rear of clouds after typhoon's invading the mainland after landing is more closely related to atmospheric circulation. In different circulation backgrounds, the influencing systems helping to causing the heavy rain of typhoon are different and the mechanism which caused heavy rain and the occurrence regions of the heavy rain of typhoon are also different. Therefore, we classified the cases of landing and impact of the heavy rain of typhoon in Fujian, according to the environments which can cause heavy rain, as well as the system conductive to the formation of the heavy rain of typhoon in such environment. They can be divided into four types (easterly jet, warm-type sheer, inverted V-shaped trough of typhoon, westerly trough). The same typhoon in different precipitation periods, if the environmental field changes, can be attributed to different types.

\section{Different Circulation Backgrounds on the Role of Heavy Rain of Typhoon}

\subsection{Easterly Jet}

\subsubsection{Situation Field Characteristics}

This type's circulation background shows that: subtropical high is zonal and its 
west ridge point is in $105^{\circ} \mathrm{E}-115^{\circ} \mathrm{E}$ and its ridge line is located in the vicinity of $30^{\circ} \mathrm{N}-32^{\circ} \mathrm{N}$. There is obviously positive height change in the northwest area of ridge line. As the typhoon moved northwest, a strong easterly jet would form between the north of typhoon and the south of subtropical high, and it makes flow field generate asymmetric structure. The strong wind speed convergence and specific topographic conditions may help spiral rainbands of typhoon develop sharply (Figure 1).

In such a situation field, the heavy rain of typhoon mainly appear in northcentral coastal areas of Fujian, which are located in the right of the forward direction of typhoon to the south side of subtropical high. The heavy rain of northeast Fujian caused by spiral rain bands of typhoon and the core of typhoon rain group occurred in this situation. From historical data analysis, it can be found that the maximum precipitation of the typhoon landing the central and southern Fujian, are mainly located in the southeast site of Jiufeng Mountain and Taimu Mountain which are located in north-central coastal area of Fujian.

\subsubsection{The Topographic Conditions under the Effect of Easterly Jet Play a Vital Role in Enlarging the Intensity of the Heavy Rain}

First of all, the particular terrain in northeast area plays a significant role in the increase of typhoon precipitation. It includes: frictional convergence of the coast and the role of the terrain uplift. According to the research, the increased precipitation caused by terrain depends on two factors: one is low-level wind speed. The stronger is wind speed, the greater is the increase. The other is the warm and humid extent of the air. The warmer and the more humid is the air, the greater is the role of terrain plays on precipitation. The northeast coast of Fujian is the rugged hills, where frictional convergence of the coast wind is particularly prominent, is often one of the larger areas of heavy rain. And there is Jiufeng

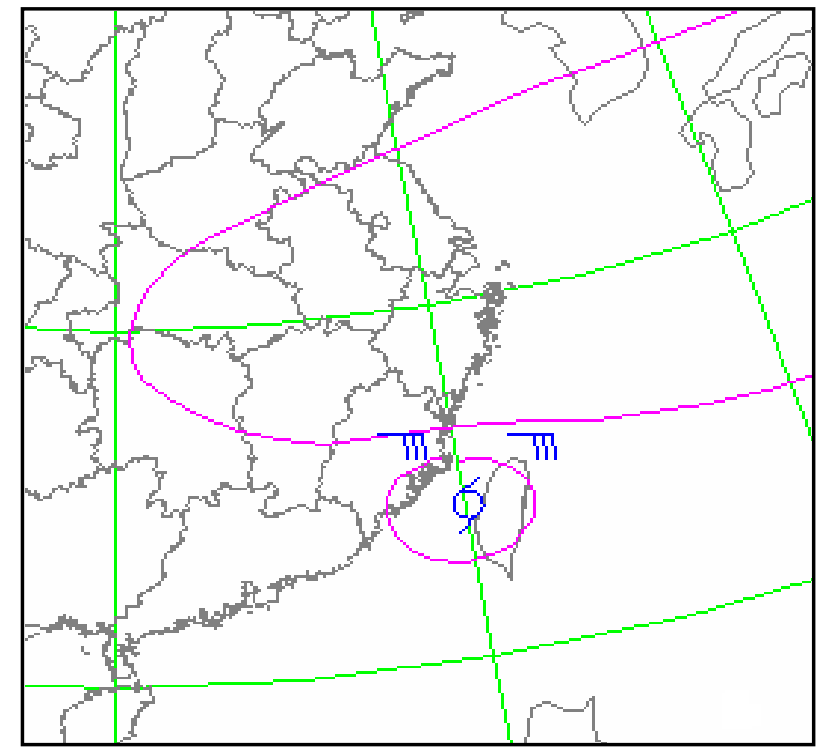

Figure 1. Easterly jet type. 
Mountain and Taimu Mountain about 1500 meters above sea level in the northeast of Fujian. They are presented the northeast-southwest direction and parallel to the coastline. In the situation field of be higher in the north and lower in the south, the east-southeast airflow of the north of typhoon and Mountains of northeast Fujian are orthogonal, and frictional convergence and the role of terrain uplift is very noticeable. In particular, Zherong, which is located halfway up Taimu Mountain, is often the "Rain vortex" of typhoons and storms in such situations. Such as the 2005 "Haitang" Typhoon, the daily rainfall of Zherong has broken the historical extreme record. As Taimu Mountain is presented the NNE-SSW direction, and is almost perpendicular to the spiral clouds band of "Haitang" typhoon. The role of blocking and forced uplift of mountain brings the occurrednce and development of convective clouds of the spiral clouds band. In 2016, Typhoon "Megi", the daily precipitation of Shouning and Pingnan on September 28th refreshed the historical extreme values of the station since the weather records. The terrain of Ningde has features of high in the northwest and low in the southeast. The precipitation of the process in Ningde City is monitored. The strong rainfall area corresponds well with the topography of Ningde. In the same way, the eastward and southeastern jets were forced to rise uphill in the windward slope of the mountain, which strengthening the rising movement of warm and moist air, and the precipitation increased significantly [3].

\subsubsection{The Converging Point of Two Airs Is Conducive to the Occurrence of Heavy Rain}

When typhoon enters the Taiwan Strait, the easterly airflow of the east of typhoon will form two airflow dues to the impact of the terrain of Taiwan. The airflow will converge once again in Fujian, the west side of Taiwan. In a case of cold air southward invasion, air meeting point not only provides strong convergence of water vapor in rainfall areas, but also forms dynamic and thermal conditions which are conducive to development of strong convective clouds. It has stimulated the development of strong convective clouds, and led to the occurrence of heavy rain in the converging point. The heavy rain processes of 0519 Typhoon "Longwang" [4], 1111 Typhoon "Nanmadol" [5], 1513 Typhoon "Soudelor" [6] and 1601 Typhoon "Nepartak" [7] have similar circulation characteristics (Table 1 ).

1111 Typhoon "Nanmadol" heavy rainstorm process [5]. It can be seen from the hourly precipitation variation in the extremely heavy rain area (Putian and Linqiao) and the analysis of the hourly ground wind field evolution from the north to the south of the Upwind Square on the east side of the mega rainstorm area (quoted from Figure 2 in [5]). On the night of August 31, the southerly wind on the east side of the low pressure circulation of 1111 Typhoon "Nanmadol" was strengthened. In the process of the gradual strengthening of the southerly wind, the wind direction on the north side of the coast of Putian has reversed, and the northerly wind has shown a tendency to gradually press southwards. The convergence zone of the northeast wind, easterly wind, and southerly 
Table 1. Precipitation extremum of several circulation similar typhoon processes.

\begin{tabular}{|c|c|c|c|c|c|c|c|c|}
\hline & \multicolumn{2}{|c|}{1111 Nanmadol } & \multicolumn{2}{|c|}{1513 Soudelor } & \multicolumn{2}{|c|}{0519 Longwang } & \multicolumn{2}{|c|}{1601 Nepartak } \\
\hline Duration & $\begin{array}{c}\text { Extremum } \\
\text { (mm) }\end{array}$ & $\begin{array}{c}\text { Station } \\
\text { name }\end{array}$ & $\begin{array}{l}\text { Extremum } \\
(\mathrm{mm})\end{array}$ & $\begin{array}{c}\text { Station } \\
\text { name }\end{array}$ & $\begin{array}{l}\text { Extremum } \\
(\mathrm{mm})\end{array}$ & $\begin{array}{c}\text { Station } \\
\text { name }\end{array}$ & $\begin{array}{c}\text { Extremum } \\
(\mathrm{mm})\end{array}$ & $\begin{array}{c}\text { Station } \\
\text { name }\end{array}$ \\
\hline $1 \mathrm{~h}$ & 99.9 & $\begin{array}{l}\text { Putian } \\
\text { Linqiao }\end{array}$ & 103 & $\begin{array}{l}\text { Zherong } \\
\text { Liushui }\end{array}$ & 168.1 & Changle & 85.2 & Minqing \\
\hline $3 \mathrm{~h}$ & 240.3 & $\begin{array}{l}\text { Putian } \\
\text { Linqiao }\end{array}$ & 164 & $\begin{array}{c}\text { Minhou } \\
\text { Xinan }\end{array}$ & 267.5 & Changle & 127.4 & Minqing \\
\hline $6 \mathrm{~h}$ & 400.9 & $\begin{array}{l}\text { Putian } \\
\text { Linqiao }\end{array}$ & 258 & $\begin{array}{l}\text { Gutian } \\
\text { XiaoJia }\end{array}$ & 280.7 & Changle & 154.8 & Minqing \\
\hline $12 \mathrm{~h}$ & 470.3 & $\begin{array}{l}\text { Putian } \\
\text { Linqiao }\end{array}$ & 339.7 & $\begin{array}{c}\text { Jiaocheng } \\
\text { Kengtou }\end{array}$ & 303.8 & Changle & 178.4 & Minqing \\
\hline $24 \mathrm{~h}$ & 501.3 & $\begin{array}{l}\text { Putian } \\
\text { Linqiao }\end{array}$ & 529.7 & $\begin{array}{c}\text { Jiaocheng } \\
\text { Kengtou }\end{array}$ & 305.7 & Changle & 186.5 & Minqing \\
\hline
\end{tabular}

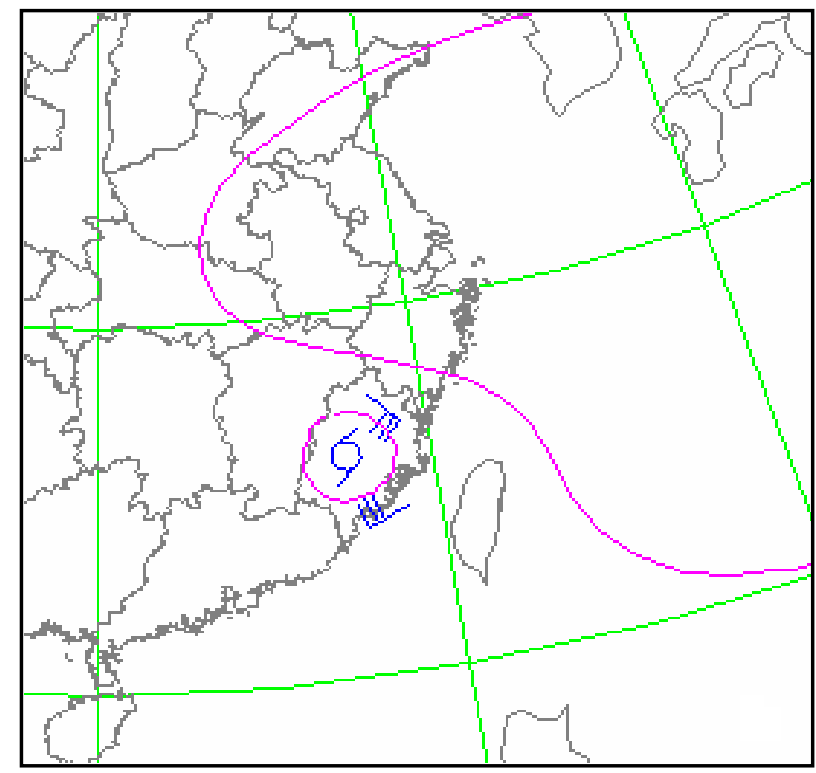

Figure 2. Warm-type sheer type.

wind appears in the Putian area. With the formation of the convergence zone, the development of mesoscale convective cloud clusters was stimulated in the convergence zone. The mesoscale convergence zone of the ground was consistent with the radar strong echo zone. The precipitation intensity of Putian and Linqiao increased sharply and maintained. The confluence of the air flow provided abundant water vapor convergence and convergent ascent power for the development of strong convective cloud clusters. Extreme heavy rain was formed on the strong convergence zone of the airflow. After 11 o'clock on the 1st, the southerly winds on the coast of Fujian weakened, and the northerly air flow in the north gradually shifted to the easterly air flow. The low-level airstream near Putian weakened and the precipitation intensity also weakened rapidly.

A detailed analysis was made of the torrential rainstorm triggered in the Fuzhou area when the Typhoon "Longwang" landed in Fujian on October 2, 2005. [4] This main reason of heavy precipitation was also that a branch of airflow 
which was formed by the role of Taiwan's terrain in the east of the typhoon system convergence again in Fuzhou. The convergence had led to the formation of convective clouds (quoted from Figure 5 in [4]). It took effect through two ways. First of all, the convergence of the airflow formed a very strong flow convergence zone in the low-level. As the strong pressure gradient between the subtropical high and the typhoon circulation, there were $20 \mathrm{~m} / \mathrm{s}$ strong wind airflow over the maintenance of low-level circulation of typhoon. The two strong airflows converged in Fuzhou and formed a very strong flow convergence zone. The convergence of airflow provided an abundant supply of moisture and convergence upward momentum for the development of convective clouds. Torrential rain was formed and developed in the strong convergence zone of the airflow.

Secondly, because of the cold air southward invasion, unstable atmospheric stratification conducive to the development of convection was formed. From the surface temperature field at 20:00 on October 2 (quoted from Figure 6 in [4]), it could be seen that there was low-level cold air from the southward invasion of the Fujian coast, and the northeast of Fujian was the temperature low value area. The east coast of the Taiwan Strait, as subsidence and warming effects of high-level easterly flow across Taiwan's Central Mountain Range, formed temperature high-value areas. It had led to the formation of strong temperature gradient between north-central coast of Fujian and the west bank of Taiwan. North branch of easterly winds by pass Taiwan Island and went through the northern Fujian, and its attributes changed. The temperature carried by air was low, which played a role in transport the cold air. When the airflow and the easterly airflow carrying large amounts of warm and humid water vapor phase in the west side of the Taiwan Strait converged, just as the convergence of two different attributes of warm and cold air, greatly enhanced unstable atmospheric stratification degree of the flow convergence region and stimulated the development of strong convection.

\subsection{Warm-Type Sheer}

\subsubsection{Situation Field Characteristics}

After the typhoon landing, there are 588 geopotential 10 meters contour lines or closed high-pressure circulation in the north of $35^{\circ} \mathrm{N}$ on the mainland. There is no high-pressure activity in south mainland of China, and the low geopotential height is conductive to typhoon convolution. The state which the subtropical high presents at sea is stable and enhancing. The areas from Northeast to North China are often the ridge areas, which superimposed on the subtropical high, with the typhoon moving northwestward, move inland other provinces. The subtropical high trails behind them, then a south-easterly wind jet appears in the east to the northeast side of typhoon, and joins with southwesterly jet in the south side of typhoon, which can form a warm-type sheer between southeast coast of Fujian and north Taiwan Strait. MCC develop rapidly in strong areas of convergent ascending movement provided by the warm-type shear (Figure 2). 
The heavy rain of such situations mainly occurs in southern region of Fujian.

We especially pay attention to the strengthening of the southwest monsoon of the South China Sea and the stability of South Asia High under this situation. For example, a big rainstorm case by "Bilis" typhoon in 2006 [8].

\subsubsection{Stable Continental High Is Conductive to Typhoon Convolution, and a Southeasterly Wind Jet Appears in the East to the Northeast Side of Typhoon}

After the Typhoon "Bilis" landed on the map at $08 \mathrm{~h} 500 \mathrm{hPa}$ on the 15th (quoted from Figure 3(d) in [8]), Lake Balkash and northeastern China were trough areas. The Baikal Lake between the two troughs was a deep warm ridge. The subtropical high was strengthening and extending into the west, and the west ridge point reached $100^{\circ} \mathrm{E}$. The main body was in the south of the Japanese island and the center reached $592 \mathrm{dgpm}$. The Hetao area was on the south side of the stable warm ridge and continued to strengthen under the superposition of warm advection and positive height. The coastal part had a breaking tendency under the action of the short wave trough in the north; the 575 dgpm low pressure in the Bay of Bengal lies at $22^{\circ} \mathrm{N}$ and $90^{\circ} \mathrm{E}$. "Bilis" lay between two high pressures. The northwestern side was a strong continental high, with northeasterly winds, southerly winds on the east, and southwesterly winds from the Bay of Bengal on the west and south. The environmental field was conducive to slower movement and the maintenance of cyclonic circulation.

This showed that after the landing of strong tropical storm "Bilis", continental high and the Western Pacific high were very strong and stable. "Bilis", which was under the block of continental high, moved slowly westward in the south side of continental high. "Bilis" low long stayed in the southern Jiangxi Province and a southeasterly wind jet maintained in the east to the northeast side of typhoon. Central and southern Fujian Province was in convergence zone of southeast wind and southwest wind in the periphery of low, and was conducive to the emergence of heavy rain. The activities of westerly trough were in the north of $35^{\circ} \mathrm{N}$, and there was no cold air invasion of typhoon.

\subsubsection{The Strengthening of the Southwest Monsoon of the South China Sea Provides Adequate Moisture and Energy for Rainfall Areas}

With the typhoon had moved westward inland, subtropical high westward extended following the typhoon. There was a strong southwesterly jet in Taiwan and the Taiwan Strait, which was in the periphery of the subtropical high. The wind speed of stream field at $500 \mathrm{hPa}$ had reached $20 \mathrm{~m} / \mathrm{s}$ or more. Westward extension of the subtropical high produced more obvious allobaric gradient, so that the large wind speed zones generated the super-geostrophic phenomenon. At the same time, the time that "Bilis" had effecting, was precisely the strong period of southwest monsoon. The southwest monsoon of the South China Sea blew $25^{\circ} \mathrm{N}$. The strong southwest monsoon of the South China Sea not only provided a sufficient latent heat to maintain strength after Bilis's landing, but also transported adequate moisture and energy over rainfall areas of southern China. 


\subsubsection{South Asia High Provides Strong Divergence for Rainfall Areas}

When "Bilis" landed South Asia High at $200 \mathrm{hPa}$ strengthened southward. (quoted from Figure 3(b) in [8]) From the Qinghai-Tibet Plateau to the eastern part of South China, it was governed by a huge amount of high pressure in South China. The high-pressure center of $1264 \mathrm{dgpm}$ was located on the west side of Hetao. "Bilis" was near the center of the bottom of the South Asian High. The southeast coastal areas of Southern Fujian and Eastern Guangdong were in the Northeast outflow of the southeast of South Asian High. "Bilis" and the rainfall areas of South China were the strong divergence zone. The subsidence effect of the centre of South Asia High was beneficial to the stability of continential high. South Asia High provided strong divergence for "Bilis" and rainfall areas and led to low-level convergence and the ascending motion strengthened, not only was conductive to the maintaince of low circulation "Bilis", but also was beneficial to the occurrence and development of MCC of the South China coast. It was a major reason for heavy precipitation after Bilis's landing.

The southeast coastal areas of Southern Fujian and Eastern Guangdong were in the Northeast outflow of the southeast of South Asian High. "Bilis" and the rainfall areas of South China were the strong divergence zone. With the strengthening and the stretching eastward and jumping northward of South Asia High, upper-level easterly jet jumped northward. Its entrance region was located over the area of low-level southwest jet. A special northeast-southwest monsoon circulation cell was formed. High-altitude areas of divergence were just to the left of low-level jet axis and the top of the rear of "Bilis". The coupling of upper-level and low-level jet streams had an important contribution to continuous heavy rain.

\subsection{Inverted V-Shaped trough of Typhoon}

\subsubsection{Situation Field Characteristics}

Before the typhoon (come from Western Pacific but move into South China Sea or come from South China Sea) landing Fujian, a inverted V-shaped trough of typhoon will form between the Taiwan Strait and the border area near $115^{\circ} \mathrm{E}$ between Jiangxi and Fujian Provinces. The two sides of inverted V-shaped trough of typhoon are made of southeasterly jet and northeasterly jet and form a strong cyclonic curvature. The southeasterly jet is a warm and moist air conveyor and produces sufficient water vapor and energy for heavy rain. The mesoscale heavy rain appears in front of the southeasterly jet of the east side of warm wet inverted V-shaped trough in low altitude. The convergence of wind speed and the air orthogonal with the mountain are conducive to the occurrence and development of MCC (Figure 3).

\subsubsection{The Steady Water Vapor Transport of Deep Wet Layer}

When the typhoon center is in the $20-22^{\circ} \mathrm{N}, 114-116^{\circ} \mathrm{E}$ near South China Sea, the central part of Guangdong, the rain clusters of mesoscale heavy rain often 


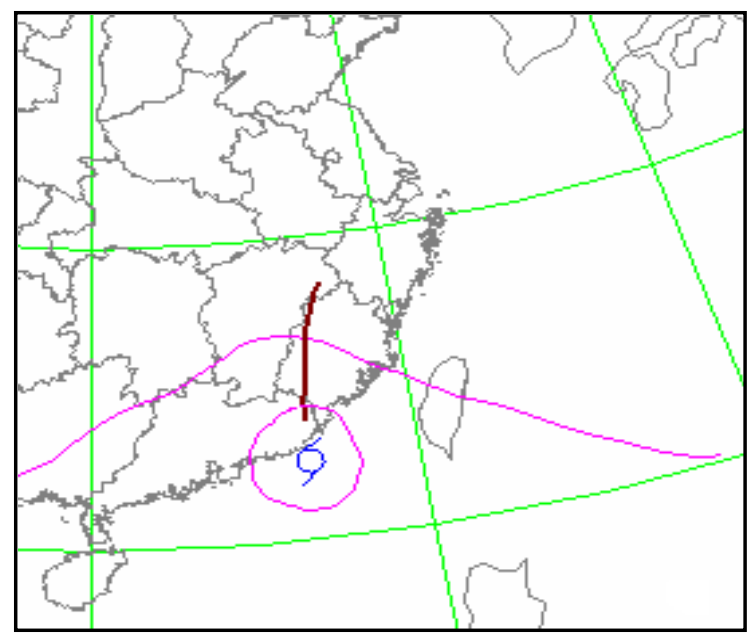

Figure 3. Inverted V-shaped trough of typhoon type.

appear in southeast Fujian in northeastern periphery of typhoon. This is mainly due to that the coastline along the Fujian coast is near the north-south direction. The high-altitude of northeast of typhoon prevails east-southeast wind, which will help the sea clouds moving along the easterly airflow and affecting southern Fujian, the rain clusters of mesoscale heavy rain appear in the northeastern part of the typhoon; and northeast of the typhoon center is usually active district of spiral rain bands of typhoon and the zone contact with the inverted trough of typhoon and the cold air, especially the typhoon circulation orthogonal with mountains is likely to develop rain clusters of mesoscale of heavy rain, and such rain clusters often occur in some special terrain of Daiyun Mountain and the east of Bo-Ping Ling Mountain in the south-central of Fujian. For example, a big rainstorm case in southern Fujian coast by 9908 typhoon (Figure 4). 1308 Typhoon "Cimaron" and 1407 Typhoon "Hagibis" (quoted from Figure 4(a), Figure $4(\mathrm{~b})$ in [9]), which had similar paths and produced extremely heavy rainstorms in Southern Fujian [9].

\subsubsection{The Invasion of Cold Air behind Westerly Trough}

Due to the rapid increase of southeast airflow of the eastern side of Typhoon inverted trough and the eastward shift of the westerly trough, the cold air behind upper-level trough forces the southeast airflow of low-level high temperature and high uplift, and results in the occurrence and development of strong convective weather of unstable regions. Heavy rain occurs in the places that typhoon inverted trough and westerly trough combine, atmosphere turns from stable stratification to unstable stratification, instability of energy rises rapidly and baroclinicity is strongest.

\subsection{Westerly Trough}

\subsubsection{Situation Field Characteristics}

When the typhoon moves closer to the coast and at the same time the westerly 


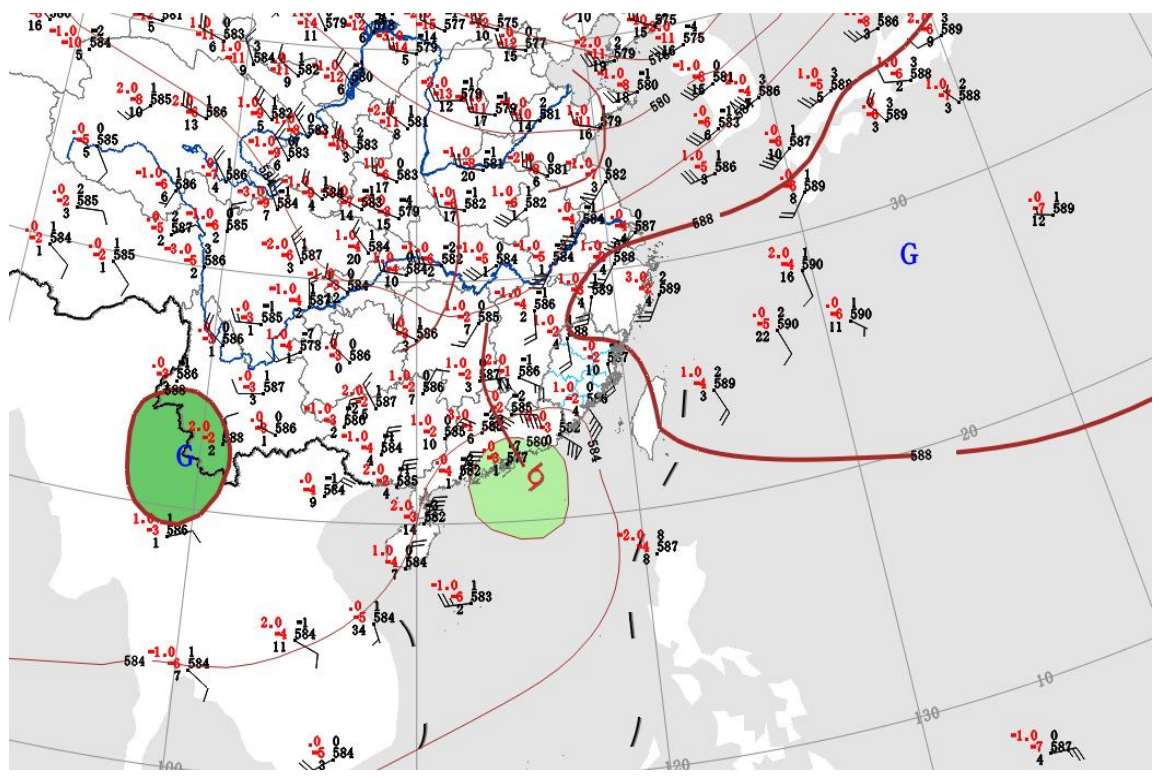

Figure 4. The situation field at $500 \mathrm{hPa}$ of 9908 typhoon.

trough moves eastwards, the typhoon may turn to northeastward without landing Fujian. However, the interaction between high-energy typhoon air and the cold air guided by the westerly trough can form unstable stratification and introduce the development of MCC. The heavy rain appears in front of westerly trough in the west of typhoon (Figure 5). If the typhoon turns around in the east of $125^{\circ} \mathrm{E}$, the heavy rain appears under the westerly trough. The heavy rain of typhoon in such situation often appears in the central and southern coastal areas in Fujian. The Forecasting is difficult, and the key is whether the eastward shift of the westerly trough is accompanied by cold air southward. For example, heavy rainfall in central and southern Fujian caused by turning and going north of 2003 "Choi-wan" typhoon. From the afternoon of September 20, 2003 to the first half of the 21st, storms and heavy rains hit the coast of the south-central Fujian Province about $1500 \mathrm{~km}$ southwest of the center of Typhoon "Choi-wan", causing serious geological disasters. This heavy rainstorm occurred after the typhoon turned northeast. Under the environmental flow of the northwesterly airstream, which is consistent from top to bottom, it is difficult to forecast [10].

\subsubsection{The Effect of Lee Waves of High-Altitude North-West Airflow Promotes the Development of Low-Level Cyclone}

"Choiwan" typhoon went northward into the westerlies, high-altitude of Fujian prevailed northwest airflows. The terrain of Fujian is high in the west and low in the east, and the mountain range has a northeast southwest trend. The effect of lee waves which generated by northwest airflow climbing Mount Wuyi promoted the formation and development of orographic depression. We can conclude from surface pressure field and 3 hours allobaric field from $19^{\text {th }}$ to $20^{\text {th }}$ that, when the high-altitude prevailed the northwest airflow, surface katallbaric centre was mainly located in the southeast of Mount Wuyi and the south of 


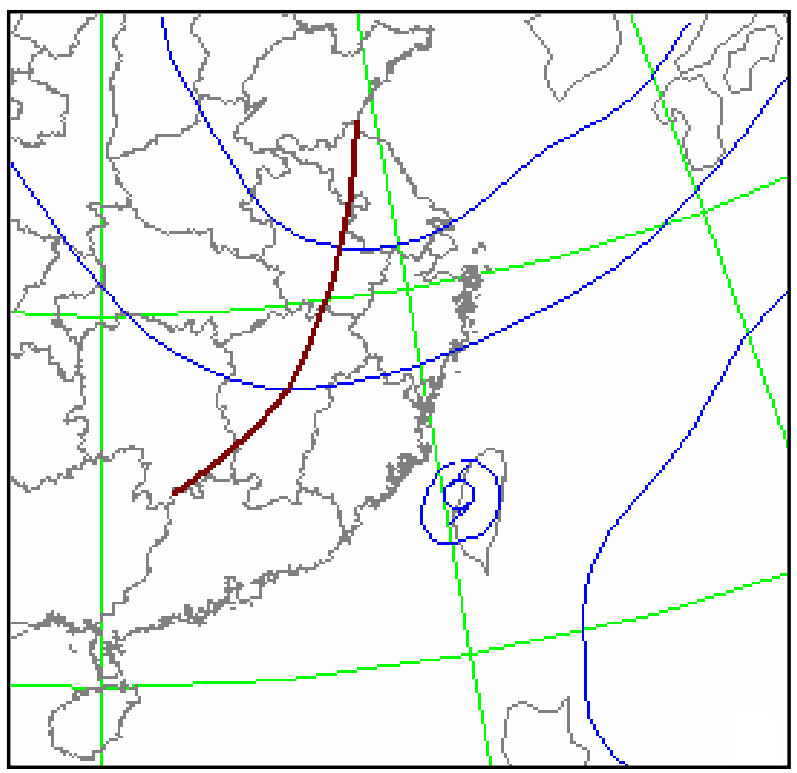

Figure 5. Westerly trough type.

Nanling, a weak low-pressure center can be analyzed in the pressure field in Fujian. Accompanied by changes in the pressure field, the wind field adapted to the pressure field, and cyclonic circulation appeared which gradually stretched upward. At 14:00 on the 20th the surface 3-hour transformer reached up to $3.8 \mathrm{hPa}$, and a strong mesoscale low pressure center appeared. At 20:00 $925 \mathrm{hPa}$ and 850 $\mathrm{hPa}$ also appeared mesoscale cyclonic circulation. It indicated that this mesoscale system which directly resulted in heavy rain was developed by orograpic circulation which caused by the northwest airflow climbing across the Mount Wuyi. Its occurrence and development had a close relationship with of the change in high-altitude field of "Choi-wan" typhoon after its turning northward.

\subsubsection{Typhoon Moves Northward into the Westerly Trough and Speeds up the Cold Air Southward}

In the early stage of the occurrence of heavy rain, at 20:00 on September 19, at $500 \mathrm{hPa}$ the subtropical areas were under the control of the two high-pressure, and the continental high was large and strong. The Middle and Upper of Fujian was under the control of the same northwest airflows. Under normal circumstances, this was an adverse weather conditions resulting in the heavy rain. However, with typhoon moving northward into the westerly trough, the trough locating in East Asia deepened, and there were obvious adjustments of circulation in East Asia. The whole westerlies moved southward, the continental high had weakened rapidly, and the extent of southward invasion of north cold air strengthened. At 8:00 on $20^{\text {th }}$, the negative variable temperature zones of the surface moved southward, 24-hour variable-temperature zero line moved to the north side of Mount Wuyi. At 20:00 on $20^{\text {th }}$, variable-temperature zero line moved to the Fujian coast. The cold air southward played an important role in the occurrence of heavy rain. Because the uplift effect of frontal surface and the 
mesoscale disturbances introduced by the cold air climbing across Mount Wuyi superimposed on the existing orographic depression, strengthened the low-level convergence and cyclonic vorticity, was conducive to trigger the formation of convective systems and provide critical dynamic triggering mechanism for the occurrence and development of heavy rainfall.

The high-energy zone of $\theta$ se appeared on September 19, but the rain appeared in the time of the low frontal zone of $\theta$ se moving southward (after 12 o'clock on the 20th, quoted from Figure 3 in [10]), the time of heavy rain occurred was consistent with the time of frontal zone transited. The distributions of rainfall areas were consistent with the direction of the dense frontal zone, because the southward process of frontal zone of $\theta$ se not only increased potential instability of prefrontal atmosphere, but also the uplift effect of frontal surface were convective to trigger the occurrence and development of convetion cells. After MCC was developed, the conversion of internal energy to kinetic energy further enhanced and convective clouds rapidly developed. It shows that the presence of high-energy zone of $\theta$ se is a condition that is conductive to the heavy rain. The southward invasion of cold air plays a key role in triggering the occurrence of heavy rain.

\section{Conclusions}

1) In different circulation situation fields, the influencing systems help to cause the heavy rain of typhoon that is different and the mechanisms which cause the heavy rain are also different. The circulation field also affects the typhoon rainfall intensity and distribution of drop zone.

2) The special geographical location and terrain in Fujian play a significant role in the increase of typhoon precipitation. It includes: frictional convergence of the coast, the role of the terrain uplift, the actions of circumferential motion and convergence of airflow, the lee effect and so on.

3) The forecasting of the heavy rain of typhoon particularly focuses on the variation of low-level jet. It includes: the intensity of low-level jet, the crossing angle between the low-level jet and the macrorelief terrain, the combination with the low-level jet and the southwest monsoon. If the system is warm-type sheer, we must particularly pay attention to the variation of the southwest monsoon.

4) If the system is easterly jet or inverted V-shaped trough of typhoon or westerly trough, we should pay attention to the effect of the cold air that causes and increases the heavy rain of typhoon.

\section{Acknowledgements}

The study was funded by the Fujian Provincial Meteorological Bureau Youth Science and Technology Special Project (2018Q01).

\section{References}

[1] Chen, Z.M., Huang, F.J. and He, G.B. (2002) A Case Study of Interactions between 
the Tropical Cyclone and the Southwest Vortex. Part I: Diagnostic Analysis. Chinese Journal of Atmospheric Sciences, 26, 352-360.

[2] Ding, Z.Y., Zhang, X.Q., He, J.H. and Xu, H.M. (2001) The Study of Storm Rainfall Caused by Interaction between the Non-Zonal High Level Jet Streak and the Far Distant Typhoon. Journal of Tropical Meteorology, 17, 144-152.

[3] Wu, X.Y., He, X.N., Pan, N., Sun, W.W. and Fan, N.Z. (2016) An Analysis of Rainstorm Process of Typhoon Megi (1617). Journal of Fujian Meteorology, 4, 6-12.

[4] Lin, Y., Liu, M., Liu, A.M. and Huang, M.J. (2007) Causation Analysis of Mesoscale Heavy Rain Triggered by Typhoon "Longwang". Meteorological Monthly, 33, $22-28$.

[5] Lin, Y., Liu, A.M. and Pan, N. (2012) An Analysis of the Causes of the Extraordinary Heavy Rainfall in the Tropical Cyclone "Nanmadol". The 29th Annual Meeting of the Chinese Meteorological Society, 12 September 2012, Shenyang.

[6] Pan, J.W., Zheng, X.Y. and Wu, W.J. (2016) An Analysis of the Cause of Heavy Rainfall in Fuzhou Caused by Typhoon 1513 "Soudelor". The 33 th Annual Meeting of the Chinese Meteorological Society, 2 November 2016, Xi'an.

[7] Lin, Y., Chen, S.X. and Lv, S.S. (2017) Analysis of Causes of Extraordinary Heavy Rain Caused by the Typhoon "Nepartak". Fujian Meteorological Observatory Technical Paper Compilation (2015-2016), Fuzhou.

[8] Liu, A.M., Lin, Y., Liu, M. and Wang, H.J. (2007) Comparative Analysis of Landing Tropical Cyclones Bilis and Kaemi with Different Rainstorms. Meteorological Monthly, 33, 36-42.

[9] Lai, H.X., Zheng, X.Q., Wu, J.C. and Chen, Y.N. (2015) Comparative Analysis on the Typhoon Rainstorms Caused by "Cimaron" and "Hagibis". Meteorological and Environmental Sciences, 38, 78-86.

[10] Lin, Y., Liu, M. and Cai, Y.Y. (2005) Formation Analysis of Sudden Heavy Rain Far from Typhoon. Meteorological Monthly, 31, 68-71. 